\title{
Los populismos y la formación del Estado-nación en América Latina
}

\author{
Francisco Entrena Durán \\ Universidad de Granada
}

Una aproximación general al fenómeno populista manifiesta que, aun cuando las diversas situaciones que han sido tipificadas como encuadrables dentro de él presentan diferencias muy acusadas entre sí, como característica común todas ellas muestran una reacción del mundo agrario contra los trastocamientos, corrupciones y otros males que, según la percepción colectiva arraigada en dicho mundo, conlleva la introducción en él de las relaciones capitalistas de producción y de mercado. Los populismos latinoamericanos son analizados aquí desde un punto de vista estructural y globalizante que los sitúa en el proceso de formación del Estado-nación. Para ello, se parte de una concepción del Estado que trata de ir más allá de la simple consideración de éste como un mero aparato político-institucional y procura abordar también las condiciones económico-sociales que constituyen su base material de sustentación, así como los marcos simbólico-legitimadores de acuerdo con los que se explica y/o justifica su orden y actuación. En consonancia con la concepción del Estado referida, el cometido central de este trabajo lo constituye el estudio de las bases económicosociales, político-institucionales y simbólico-legitimadoras de los Estados populistas latinoamericanos. Entre otros diversos aspectos, dicho estudio permite concluir cómo, a diferencia de la generalidad de los populismos en los que el Estado y lo político-urbanoindustrial son percibidos sobre todo como referentes de rechazo, en América Latina es desde el propio Estado, desde donde se impulsaron los proyectos populistas.

\section{Aproximación general al fenómeno populista}

"En mi opinión, parece difícil encontrar un asunto más tratado por la teoría política del siglo XX, que el populismo; y, al mismo tiempo, otro asunto, de tan grande importancia, que haya inspirado tan pocos análisis serios y objetivos. Aparentemente, la mayoría de las personas se encuentran tan ocupadas en acusar o defender el populismo, que no les sobra tiempo suficiente para dedicarse a su estudio serio, profundo y responsable".

La propia indefinición del vocablo pueblo al que de una u otra forma alude la palabra populismo está en el origen de la usual ambigüedad e imprecisión de la misma. En realidad, el pueblo es un sujeto heterogéneo y diverso, así como objeto ambivalente de repudios (se trata de aquellos que lo tipifican como fácilmente adulable y manipulable por parte de los dema-

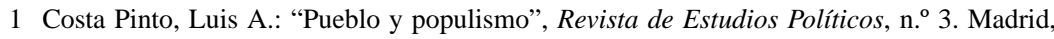
mayo-junio 1978, pág. 37. 
gogos populistas) o de ensalzamiento. Esta es la postura de los que, comulgando con las ideologías populistas, nos las presentan como la voz del pueblo, que es concebido por ellos como la reserva de todas la virtudes frente a la corrupción urbana. Así sucede, por ejemplo, en los casos de Rusia y EE.UU., respecto a los que aquí se hará una breve referencia. En tales planteamientos subyace una especie de maniqueísmo, similar al existente en ciertas concepciones más o menos vulgarizadas del marxismo, para las que el proletariado es algo así como la encarnación universal del sujeto salvífico de la historia, frente a la burguesía que simboliza todos los males. Pero, también dicha ambigüedad se debe a que el término populismo suele ser empleado por los que lo utilizan desde perspectivas teórico-ideológicas muy dispares, a la vez que para aludir a una gran diversidad de situaciones muy heterogéneas y diversas. Una muestra de esa heterogeneidad de situaciones es que la historia político-social de diversos países europeos, asiáticos o africanos, e incluso la de los Estados Unidos de Norteamérica, presenta movimientos de masas, partidos políticos y formas de gobierno que han sido denominados con la etiqueta de populismos. Como una muestra de ello, aquí se hará brevemente mención a los fenómenos populistas ruso y norteamericano, que constituyen dos casos bastante representativos.

En la Rusia zarista, hacia la década de los setenta del siglo XIX, arraigó una forma de populismo agrario que constituyó un foco de aglutinación ideológica de la desarticulada oposición zarista. ${ }^{2}$ Los intelectuales que estaban cerca de los populistas consideraban la economía campesina como una estructura social específica de naturaleza no capitalista. Para ellos, la unidad campesina se encontraba inmersa en el contexto social de una economía seminatural, ubicada bastante al margen del ámbito de las relaciones de mercado, de la economía monetaria y de la modalidad de producción motivada por la mera obtención del beneficio. ${ }^{3}$ Dada su proximidad con ellos, dichos intelectuales participaban de puntos de vista muy análogos a los de los propios campesinos populistas, cuyas actitudes y formas de acción colectiva se centraban en: 1) la batalla contra la mercantilización de sus intercambios, tanto con la naturaleza como con la sociedad, a que les forzaba el proceso de privatización que conllevaba el avance del capitalismo; 2) el escepticismo ante las formas de participación política típicas de la democracia formal; 3) la existencia en su colectivo de valores éticos e

2 Ebenstein, W.: Los Grandes Pensadores Políticos, Madrid, 1965, pág. 830.

3 Shanin, Teodor: La clase incómoda. Sociología política del campesinado, Madrid, 1983, pág. 91.

102

Anuario de Estudios Americanos 
igualitarios que eran considerados como inherentes a las leyes de la naturaleza; 4) la propiedad colectiva con posesión individual de los recursos naturales, y 5) la autorregulación política a nivel local. ${ }^{4}$

El populismo norteamericano se desarrolló a finales del siglo XIX entre propietarios y trabajadores agrícolas. ${ }^{5}$ Por esas fechas el sector capitalista de la economía agraria estadounidense atravesaba una crisis de superproducción, a la vez que, paralelamente a ello, perdía importancia relativa y absoluta frente al capital industrial, comercial y financiero. La retórica y la ideología de este populismo manifestaba una pretensión de conservar las que se consideraban como saludables cualidades de la sociedad rural contra el debilitamiento que introducían en ella fuerzas sociales extrañas. Su finalidad era impedir la desintegración de las comunidades campesinas y el deterioro del modo tradicional de vida agrario, así como preservar el mantenimiento de una identidad rural autónoma. ${ }^{6}$ En definitiva, se manifiesta aquí la preocupación por mantener los valores jeffersonianos de la comunidad y de la democracia rurales.

Asimismo, los populistas norteamericanos consideraban la tierra como la más importante fuente de riqueza y de bienestar social, al mismo tiempo que se quejaban de los "parásitos" y de los "ladrones" que controlaban el comercio, las finanzas y el aparato del Estado, en perjuicio de los que "de verdad trabajaban y producían". Se trataba de una peculiar negación de la economía del laissez faire que abogaba por una intervención estatal en los asuntos económicos, en especial los relacionados con el capital financiero, que era percibido como una vía por la que se evadían gran parte de los beneficios obtenidos en la agricultura. El agricultor tenía que soportar una serie de políticas impositivas y arancelarias, y, aunque sujeto a un sistema de producción organizado en multitud de pequeñas unidades que funcionaban a costes fijos, debía efectuar sus ventas en un mercado cada vez más competitivo. Si bien sus exportaciones contribuían a sufragar el capital importado preciso para la financiación de la industria norteamericana, lo cierto es que su trabajo producía, a un precio cada vez más bajo, los alimentos que nutrían a los obreros industriales. Y, a pesar de todo ello, a medida que pasaba el tiempo, el agricultor veía cómo sus ganancias no

\footnotetext{
4 Referido en Barragán, A.; González, M., y Sevilla, E.: "Revueltas campesinas en Andalucía”, Cuadernos de Historia 16, n. ${ }^{\circ}$ 294, Madrid, 1985, pág. 6.

5 Ianni, Octavio: La formación del Estado populista en América Latina, México, 1975, pág. 35 .

6 Newby, H. y Sevilla-Guzmán, E.: Introducción a la sociología rural, Madrid, 1983, pág. 26.
} 
estaban en proporción con lo que él creía que era su aportación al crecimiento nacional. ${ }^{7}$

Aun cuando las diversas situaciones que han sido tipificadas de populistas muestran acusadas diferencias entre sí, como característica común a todas ellas se puede afirmar que, por lo general, el populismo se ha manifestado como una reacción del mundo agrario contra los trastocamientos, corrupciones y otros males que, de acuerdo con la percepción colectiva arraigada en dicho mundo, conlleva la introducción en él de las relaciones capitalistas de producción y de mercado. En consonancia con estos planteamientos, en casi todas las formas de populismo se trata de ensalzar y conservar el modo de vida de base agraria. Lo industrial-urbano es relegado como pernicioso, o en un nivel más secundario visto como una actividad subordinada. Se considera la tierra como la más importante, cuando no la única, fuente de riqueza y de bienestar social. ${ }^{8}$ Todo progreso económicosocial, cultural o político es afrontado en términos de preservación y revalorización de las experiencias de carácter comunitario o tribal del mundo tradicional.

\begin{abstract}
"En todos estos países que han conocido movimientos populistas expresivos, él ha representado siempre la ideología de las virtudes del pasado contra los males del presente y las incertidumbres del futuro; siempre ha defendido los estilos considerados auténticos, tradicionales, rurales, de folk, contra los estilos urbanos ecuménicos, universales". ${ }^{9}$
\end{abstract}

\title{
Los populismos latinoamericanos: un modelo de análisis
}

A pesar de la diversidad nacional de América Latina, es indudable que pueden apreciarse notables semejanzas y convergencias entre los diferentes y heterogéneos países que componen este entorno geopolítico. En determinadas ocasiones, estas convergencias y semejanzas se acentúan de tal manera "que varios, o la mayoría, de los países parecen vivir y pensar problemas muy similares". ${ }^{10}$ Un ejemplo especialmente significativo de tales

\footnotetext{
7 Hofstadter, Richard: "Estados Unidos", en Gellner, Ernest e Ionescu, Ghita (Compiladores): Populismo. Sus significados y características nacionales, Buenos Aires, 1969, págs. 19-20.

8 Ianni, O.: La formación del Estado..., pág. 29.

9 Costa Pinto, L. A.: "Pueblo y populismo", pág. 38.

10 Ianni, O.: "La idea de América Latina", en Roitman, Marcos y Castro-Gil, Carlos: América Latina: entre los mitos y la utopía, Madrid, 1990, pág. 51.
} 
ocasiones es la coyuntura histórica en la que, en la generalidad de las naciones latinoamericanas, se desarrollaron los fenómenos populistas, a tres de los cuales se hará referencia brevemente a continuación.

En 1930 Getulio Vargas asumió el poder en Brasil proclamando como objetivos el saneamiento del sistema electoral, la lucha contra el desorden y la regeneración de la vida política. Permaneció durante cuatro años como jefe de un gobierno provisional y, después de la promulgación de la Constitución de 1934, resultó elegido por la Asamblea Nacional presidente de la Segunda República brasileña por un período de mandato de cuatro años. Sin embargo, en 1937, Vargas se proclamó dirigente del llamado Estado Novo, de carácter corporativista y permaneció en el poder hasta 1945, fecha en que fue derrocado por un golpe de Estado. En 1951, después de haber resultado vencedor en unas elecciones democráticas celebradas en el año anterior, Vargas accedió de nuevo a la presidencia y se mantuvo en ella hasta su suicidio en agosto de 1954..$^{11}$ Concluía de esta forma una de las más importantes experiencias populistas latinoamericanas. El modelo sindical impulsado por el varguismo, de acuerdo con la naturaleza corporativista del régimen que lo sustentaba, tenía como objetivo principal una "política de paz social", tendente a fomentar la colaboración entre las clases. De este modo, los trabajadores podían experimentar la "ilusión" de compartir con la burguesía la responsabilidad de la orientación política del país. ${ }^{12}$

$\mathrm{Al}$ igual que en Brasil, en Argentina el surgimiento y desarrollo del populismo estuvo también muy vinculado al destino de una figura personal. Se trata de Juan Domingo Perón, que, elegido presidente de la República en 1946, permaneció en el poder hasta 1955, fecha en que la oposición de la Iglesia y de las fuerzas armadas desembocó en un descontento general que le llevó a renunciar. Tras dieciocho años de exilio retornó a su país y fue elegido presidente de la República en 1973, pero ya no volvió a repetirse la política de "conciliación" de los intereses del movimiento obrero con los del capital que había caracterizado el populismo peronista de la primera etapa. Perón permaneció en el cargo hasta su muerte en 1974.

Aparte del peronismo argentino y del varguismo brasileño, cabe destacar también el cardenismo en México. Se trata del régimen instaurado en este país por Lázaro Cárdenas, que gobernó entre 1934 y 1940. La intensa

11 Hidalgo Da Silva, Osvaldo, y Moyano, Eduardo: "Acción colectiva y asociacionismo agrario en Brasil", Agricultura y Sociedad, n. ${ }^{\circ}$ 68-69, Madrid, julio-diciembre de 1993, pág. 229.

12 Fernández Franco, Lorenzo: Estructura y clases sociales en la América Amazónica, Madrid, 1992, pág. 12. 
reforma agraria, la conversión del Partido Nacional Revolucionario (PNR), creado por Plutarco Elías Calles en 1929, en el Partido de la Revolución Mexicana (PRM) y su consiguiente transformación en un instrumento del Estado para la movilización de las masas, el encauzamiento y el control de las demandas de éstas fueron, junto con las disposiciones nacionalizadoras de los sectores económico-productivos básicos, los factores fundamentales sobre los que se sustentó la política populista de masas llevada a cabo por Cárdenas. ${ }^{13}$ Factores, a partir de los cuales fue posible la articulación de una forma de Estado, cuyo entramado institucional y dinámica de funcionamiento estaban en condiciones de propiciar por sí mismos el desarrollo de políticas de orientación populista. Se configuró de este modo el populismo estructural típico del régimen mexicano. Populismo estructural, ya que, a diferencia de la marcada orientación personalista del peronismo o del varguismo, que estuvieron en gran parte vinculados a las capacidades de mando y facultades de los líderes que los impulsaron, y por lo tanto no sobrevivieron a tales líderes, en México se asentó, a raíz de las reformas llevadas a cabo por Cárdenas, una fórmula de dominación populista más vinculada a la naturaleza institucional del sistema que a las mayores o menores facultades carismáticas que, individualmente, haya podido tener cada uno de los presidentes concretos que se han sucedido en el cargo a partir de entonces.

El varguismo, el peronismo y el cardenismo son los Estados populistas tomados en consideración en esta breve referencia porque se estima que estos tres casos manifiestan las características fundamentales del conjunto de tales Estados. En cualquier caso, que el estudio de los populismos latinoamericanos sea afrontado aquí de manera conjunta, no implica la presuposición de que todos los regímenes latinoamericanos de esta naturaleza sean considerados idénticos; de hecho, cada uno de ellos tiene características específicas en función de sus respectivas situaciones sociohistóricas particulares.

Habitualmente los estudios que se han dedicado al análisis de los populismos han abordado la cuestión de manera fragmentaria e incompleta; es decir, se han limitado sólo a la consideración de unas determinadas características. Así, frente a las perspectivas que enfatizan la modernización y el cambio social y a aquellas que se centran en la manipulación

13 Véase a este respecto Córdova, Arnaldo: La política de masas del cardenismo, México, 1974.

106

Anuario de Estudios Americanos 
demagógica llevada a cabo por los líderes populistas (Germani, Di Tella, Graciarena), Ianni, desde un punto de vista bastante imbuido de los planteamientos marxistas, destaca la naturaleza contradictoria de las alianzas de clase que eventualmente se establecen al amparo de la coyuntura populista, las notables diferencias de actitudes y de expectativas que, como consecuencia de ello, tiene cada una de las clases sociales implicadas en el proyecto socio-político populista, las estrechas conexiones que hay entre bonapartismo y pacto populista, o las relaciones existentes entre una fase del desarrollo capitalista en países dependientes como los latinoamericanos y la emergencia del populismo. ${ }^{14}$

La intención que subyace a la estrategia analítica adoptada en el presente trabajo, más que aportar nuevas características (tarea que, además de extremadamente difícil, dado el gran número de estudios efectuados sobre el tema, no se considera que contribuya mucho a aclarar la naturaleza de los populismos latinoamericanos), es proceder a una sistematización e integración en un marco común de los rasgos ya referidos por otros estudiosos de esta cuestión.

Toda realidad social es en mayor o menor medida compleja, cambiante y circunstancial, a la vez que difícilmente encuadrable en el marco, en cierto modo restrictivo, de cualquier modelo teórico. Cuando se trata de abordar el estudio de un fenómeno social, la opción más sensata parece ser elaborar un modelo lo más apropiado posible para poner en práctica una estrategia de análisis con la que caracterizar adecuadamente tal fenómeno. En el presente caso, en el que se pretende elaborar un modelo teórico con el que poner de manifiesto la estrecha relación que existe entre el arraigo del fenómeno socio-político populista y el proceso global de formación del Estado-nación en la realidad latinoamericana, las dificultades se acrecientan debido a que esta realidad es y ha sido siempre especialmente convulsa y contradictoria. Para lograr el propósito de conceptuar globalmente dicho proceso, se considera que lo más adecuado es partir de un planteamiento del Estado que trate de ir más allá de la simple concepción de éste como un mero aparato político-institucional y procure abordar también las condiciones económico-sociales que constituyen su base material de sustentación, así como los marcos simbólico-legitimadores de acuerdo con los que se explica y/o justifica su orden y actuación. El objetivo es comprender el Estado populista desde un punto de vista estructural y globalizante,

14 Ianni, O.: La formación del Estado.... 
en el que se contemplan como estrechamente integradas y vinculadas entre sí las bases económico-sociales, político-institucionales y simbólico-legitimadoras de dicho Estado. De este modo, los populismos latinoamericanos son presentados aquí como formas de articulación y/o tentativas de institucionalización del poder estatal, y del discurso legitimador del mismo, conformadas/conformadoras de/por un estadio en la evolución de las heterogéneas y contradictorias estructuras económico-sociales.

\section{Las bases económico-sociales}

Los populismos latinoamericanos surgieron cuando, después de la gran depresión económica de los años treinta, entró en crisis en América Latina el sistema de poder oligárquico. A raíz de ello se empezó a dejar de lado el modelo liberal ortodoxo que, sustentado en los principios de la división internacional del trabajo, había asignado a esta región del mundo la función de producir materias primas (especialmente, agrarias) destinadas a la exportación. La política económica optaba, a partir de esas fechas, por impulsar un movimiento de industrialización encaminado a la elaboración autóctona de productos que hasta ese momento habían procedido de la importación, a la que se le pusieron notables barreras arancelarias. Como consecuencia de la industrialización se experimentó una intensificación de los niveles de diferenciación interna y de especialización funcional de los sistemas económicos, incrementándose, a raíz de ello, el peso relativo y absoluto de los sectores secundario y terciario.

La industrialización, amparada en la sustitución de importaciones, posibilitó un creciente ascenso del nivel de ocupación y, aunque resultaba más caro producir los productos que importarlos de fuera, lo cierto es que de ella se derivó un considerable incremento de la productividad y de los ingresos netos en el conjunto de la economía. Todo ello se tradujo en un significativo aumento del nivel de integración del mercado a escala nacional, lo que, a su vez, puede considerarse como un requisito especialmente necesario para posibilitar el afianzamiento del Estado-nación..$^{15}$

La otra cara de la política de sustitución de las importaciones es que las excesivas, cuando no abusivas, trabas que se le impusieron a las impor-

15 Un interesante y sugerente ensayo a este respecto es Moya, Carlos: "Estado nacional y mercado nacional", en Moya, Carlos: Señas de Leviatán. Estado nacional y sociedad industrial: España 1936-1980, Madrid, 1984 
taciones contribuyeron a quitarle incentivos a las industrias nacionales para modernizarse, mejorar sus métodos de producción e ir acomodándose gradualmente a las exigencias de la competitividad internacional. De este modo, se estaba, ya desde los mismos comienzos del proceso de industrialización, gestando el embrión de las futuras crisis y brutales regresos a la ortodoxia liberal, que tan funestos efectos tuvieron en los años setenta y ochenta, en lo referente a propiciar el desmantelamiento de las deterioradas y poco competitivas estructuras industriales de ciertos países del cono sur latinoamericano.

Los procesos de modernización e industrialización dieron también lugar a una elevación de los niveles de emigración de la población rural a las ciudades. El crecimiento de las urbes, que como consecuencia de ello tuvo lugar, propició unas condiciones muy adecuadas para una irrupción de las masas en la escena socio-política, a la que estuvo muy vinculado el surgimiento de los regímenes populistas latinoamericanos. En particular, los populismos aparecieron como fenómenos muy relacionados con las exigencias de democratización y de mayor participación colectiva en los bruscos procesos de cambio social o de modernización inherentes al tránsito de una sociedad tradicional arcaica o rural a otra de naturaleza moderna, urbana o industrial. Estas repentinas transformaciones de las sociedades latinoamericanas generaron una especie de "revolución de las expectativas" sociales en las masas urbanas de recién llegados del campo, que poseían una escasa o nula comprensión de los valores y patrones socioculturales de la ciudad, lo que las hacía fácil presa de la eventual "demagogia" de los líderes populistas. Gino Germani considera que tales masas no poseían todavía las condiciones psicosociales, o paradigmas de cultura política, que se suponen consustanciales a las formas de acción colectiva urbanas y democráticas; se hallaban en un proceso de resocialización que conllevaba una modificación de sus expectativas y actitudes. Este autor concibe los populismos, o movimientos nacional-populares como él los llama, como fenómenos socioculturales y políticos típicos del período de transición de la sociedad tradicional a la urbana industrial. En ese período se produce una situación singular como consecuencia de la existencia de lo que él denomina la "simultaneidad de los no contemporáneos". En realidad, esta sincronía de lo contradictorio suele ser una característica bastante arraigada en la economía, la cultura, la política y otras manifestaciones de Latinoamérica, que ha sido conceptuada como una sociedad dual: 
“...todos los aspectos de la estructura social pueden ser asincrónicos: tanto sus elementos psicológicos como la 'superficie' material y ecológica. Dentro de la misma región -lo mismo que dentro de regiones ecológicamente diferentes-, coexisten grupos 'avanzados' y grupos 'atrasados'. Unas normas contradictorias (las correspondientes a unos estadios anteriores de la sociedad y las que surgieron bajo el efecto de cambios de diversa índole, producidos en otros sectores de la estructura) pueden continuar rigiendo la misma institución con tal que unas y otras guarden cierta legitimidad. De modo análogo, pueden coexistir actitudes, creencias y valores que "corresponden' a épocas diversas". ${ }^{16}$

De acuerdo con Germani, las etapas del desenvolvimiento histórico de América Latina son las siguientes:

1) guerras de emancipación colonial y proclamación formal de la independencia política;

2) guerras civiles, caudillismo, anarquía;

3) autocracias unificadoras;

4) democracias representativas de participación restringida;

5) democracias representativas de participación amplia;

6) democracias representativas de participación total;

7) revoluciones nacional-populares, que surgirían como una alternativa a las tres modalidades de democracia antes referidas.

La llamada "democracia de participación restringida" es un sistema que, aunque formalmente se manifiesta como democrático, sólo permite la actuación política de la oligarquía. El paso a la "participación amplia" se lleva a cabo cuando existen clases medias importantes con capacidad y voluntad de actuar en el plano político. Como sostiene Carlos M. Rama, Germani toma casi exclusivamente en consideración la evolución seguida por Argentina, y especialmente la experiencia política peronista, que se situaría en el séptimo estadio del esquema de desarrollo antes propuesto. Asimismo, Germani tiene más en cuenta las formas de gobierno que la estructura del Estado, la naturaleza y las atribuciones del poder en que tales formas se sustentan. ${ }^{17}$

En definitiva, la interpretación de Germani enfatiza los aspectos autoritarios o demagógicos del populismo, fenómeno que, aunque situado por el autor en el estadio más alto del esquema evolutivo de la historia política lati-

16 Germani, Gino: "Democracia representativa y clases populares en América Latina", en Alain Touraine y Gino Germani: América del Sur: un problema nuevo, Barcelona, 1965, pág. 40.

17 Rama, Carlos M.: Sociología de América Latina, Barcelona, 1977, pág. 135. 
noamericana que se acaba de exponer, es presentado, sin embargo, como un retraso en lo que se supone como el ineludible proceso hacia una forma de democracia bastante acorde con la vigente en las sociedades europeas y occidentales avanzadas. Este punto de vista refleja, a mi entender, el eurocentrismo y el unilinealismo evolutivo inherentes a determinadas perspectivas de la modernización, que suelen presuponer que la evolución de todas las sociedades ha de ajustarse necesaria e inevitablemente al proceso histórico y sociopolítico seguido por el mundo desarrollado occidental. En cualquier caso, nada más lejos de mi intención que abogar por una especie de reivindicación de unas supuestas especificidades internas consustanciales a los procesos de evolución sociopolítica de Latinoamérica, lo que podría presentar como deseable la opción por esa modalidad de caudillismo y falta de democracia que, a fin de cuentas, existió durante los populismos. ${ }^{18}$ Lo que aquí se está cuestionando no es la ineludible exigencia de transitar hacia la democracia, sino la limitada validez explicativa de las teorías de la modernización, dentro de las que se inserta la aportación de Germani. Validez limitada porque dicha aportación participa de una visión lineal y universalista que supone una única vía en la evolución del desarrollo económico-social y en el tránsito hacia la democracia. Tránsito que es concebido como si solamente se tratara de superar una serie de estadios, análogamente a las etapas que Rostow estableciera para el crecimiento económico, ${ }^{19} \mathrm{y}$ no hubiera que vencer también los obstáculos al desarrollo derivados de la naturaleza dependiente de las estructuras de clases, económicas y sociopolíticas de Latinoamérica. De hecho, el surgimiento, la evolución y las características peculiares del populismo latinoamericano están estrechamente vinculadas con las transformaciones y reajustes que se producen en las bases económico-sociales de esa dependencia a raíz de distintos acontecimientos históricos. Así, la aparición y desarrollo de los regímenes populistas tiene lugar cuando se experimenta una recomposición del modelo de dependencia agrario-exportador vigente durante los regímenes oligárquicos. Recomposición que se produce como consecuencia del declive de las oligarquías liberales o autoritarias formadas en el siglo XIX y del estado de relativa autonomía que adquieren las sociedades latinoamericanas cuando las potencias imperialis-

18 Por referir un ejemplo a este respecto, hay quien ha considerado que, más que una lacra social, el caudillismo latinoamericano constituye un rasgo prototípico, una especie de originalidad esencial que, a fin de cuentas, "es la manifestación más genuina del temperamento de la raza". Carro Martínez, Antonio: "El caudillismo americano", Revista de Estudios Políticos, n. ${ }^{\circ}$ 93, Madrid, 1957, pág. 150 .

19 Rostow, W.: Las etapas del crecimiento económico, México, 1963. 
tas de Europa y Norteamérica entran en crisis y su atención se orienta, como consecuencia de la II Guerra Mundial, hacia otras partes. En estas circunstancias se abren nuevas posibilidades para la reorganización del aparato del Estado como una entidad legitimada en un nacionalismo globalizante, en el seno del cual las masas aparecen como un elemento político importante y a veces decisivo. Asimismo, es precisamente el carácter dependiente de tales sociedades el que explica el relativamente fuerte arraigo del antiimperialismo y del nacionalismo de la retórica típica de estos regímenes populistas, en tanto que expresiones encaminadas a satisfacer la necesidad psicológica colectiva de reafirmación de la independencia y de la autonomía de acción frente al exterior. No se trata aquí, como en los otros casos de fenómenos populistas referidos al comienzo de este trabajo, de un enfrentamiento de la sociedad agraria tradicional contra el Estado industrial modernizador, sino del grueso de las sociedades latinoamericanas, coaligadas en el contradictorio, inestable y frágil frente policlasista característico de los populismos, articulando conjuntamente un proyecto de Estado-nación contra las consideradas como abusivas injerencias del capitalismo mundial, del imperialismo extranjero y de sus aliadas internas las clases oligárquicas.

Como una muestra de las contradicciones y heterogeneidad de esta coalición policlasista, que son una constante en todos los populismos, puede citarse el caso argentino, cuyo líder, Juan Domingo Perón, sirviéndose de una difusa terminología, tuvo la habilidad de aglutinar en torno a él a un amplio espectro de grupos sociales, entre los que se encontraban incluso sectores de la extrema derecha nacionalista. ${ }^{20}$ Sectores, que sólo tenían en común el rechazo a la dependencia del exterior y su anhelo por un capitalismo nacional autóctono.

Análogamente a Argentina, en los otros regímenes populistas las contradicciones de las características coaliciones policlasistas a las que dieron lugar derivan, en gran medida, de las divergencias de intereses entre los diversos sectores que las integraron. Divergencias que implican que, en realidad, pueda hablarse de varias visiones del populismo. Una de ellas es el enfoque que de éste se hace desde la cúspide de la pirámide social, es decir, desde la perspectiva de los gobernantes, los políticos profesionales, la burguesía nacional, los falsos líderes obreros o los demagogos. ${ }^{21}$ Se trata, en este caso, del populismo propugnado por las élites burguesas y de clase

20 Martínez Díaz, Nelson: "El Peronismo”, en Cuadernos de Historia 16, n. ${ }^{2}$ 293, Madrid, 1985 , págs. 10 y 11 .

21 Ianni, O.: La formación del Estado..., págs. 18-19. 
media, que se sirven tácticamente de las masas trabajadoras y de los sectores más bajos de las clases medias. Ese populismo manipula a las masas obreras, a la vez que instrumentaliza las manifestaciones y las potencialidades de su conciencia. Por otra parte, es preciso analizar esa modalidad de populismo de la que participan las propias masas; es decir, los obreros, los inmigrantes de origen rural, los grupos pertenecientes a los escalones más bajos de las clases medias, los estudiantes universitarios de ideología radical, los intelectuales de izquierda y los partidos políticos de esta ideología.

En los primeros momentos de emergencia y afianzamiento de la coalición populista parece existir una amplia armonía entre las dos modalidades de populismo que se acaban de referir. No obstante, cuando sobrevienen las situaciones críticas y las contradicciones de naturaleza política y económica se agudizan, entonces suelen ponerse de manifiesto los antagonismos e incompatibilidades entre las clases que permanecían latentes en los momentos de máxima confluencia de la coalición. En tales circunstancias, mientras que el primero de los populismos antes mencionados no duda en abandonar a las masas o, en ocasiones, también recurre a reprimirlas a fin de impedirles que sigan avanzando en sus conquistas políticas, el populismo del que participan directamente las masas tiende a radicalizar sus planteamientos e, incluso, a encaminarse hacia formas revolucionarias. En ese contexto puede ocurrir la transformación del movimiento populista de masas en un conflicto muy similar al etiquetado desde la perspectiva marxista como de lucha de clases.

Al mismo tiempo que las oligarquías tradicionales parecían tender a disminuir, los obreros urbano-industriales y las clases medias se ampliaron y afianzaron su posición como consecuencia de las transformaciones económicas que se estaban experimentando a raíz de la industrialización propiciada por los regímenes populistas. Industrialización que dio lugar a un considerable aumento de la demanda de niveles más elevados de cualificación y de especialización profesional, a la vez que estuvo asociada a la aparición de otras modalidades de organización social, burocrática y político-institucional en consonancia con el incremento de la complejidad y del grado de especialización funcional que, como consecuencia de todos estos cambios, se estaba generando. En este contexto, las masas trabajadoras empezaron a dejar de lado las pautas socioculturales que se gestaron y estaban en vigor cuando predominaban las oligarquías. ${ }^{22}$ Los valores

22 Ibídem, pág. 18. 
económicos, sociales o religioso-culturales aún bastante impregnados del espíritu de comunidad iban, paulatinamente, siendo relegados y reemplazados por valores generados en el ámbito urbano-industrial. De esta forma, los obreros fueron pasando, poco a poco, de la usual inmediatez de las relaciones de tipo comunitario a la mayor complejidad y alta cota de formalización que suelen ser características de los grupos secundarios. En las nuevas formas de relación entre el trabajador, los instrumentos de producción y el producto de la fuerza de trabajo que iban emergiendo, los componentes mágicos o animistas iban, gradualmente, siendo relegados en aras de la subordinación a las exigencias impuestas por el ritmo y la escala de la producción.

Los regímenes populistas contribuyeron a aglutinar a una gran diversidad de intereses y de tendencias, de acuerdo con el carácter policlasista de la sociedad en la que se desarrollaron y arraigaron. Una sociedad que encontró, de esta forma, una fórmula mediante la que aglutinar en una especie de síntesis coyuntural integradora a escala nacional el alto nivel de desestructuración que la caracterizaba. Síntesis coyuntural, porque tan heterogénea y diversa agrupación de intereses sólo resultó viable en la ocasión de relativa bonanza de la economía y de buenas expectativas en la que se fraguó. Sin embargo, cuando posteriormente sobrevino la recesión y la crisis, la movilización de las masas comenzó a ser vista, precisamente por parte de aquellos sectores de las clases medias y altas que originariamente habían confluido en el pacto policlasista, como algo que amenazaba el statu quo de las oligarquías, contra cuyos privilegios el enfrentamiento de los populismos nunca llegó, en realidad, mucho más allá de la mera retórica formal que legitimaba su actuación. En este contexto, comenzaron a ser frenadas e incluso reprimidas las estrategias movilizadoras por parte de los mismos regímenes populistas que originariamente las habían impulsado. En definitiva, la naturaleza corporativista de los sistemas populistas y las políticas de armonización de clases, en las que los mismos se apoyaron, contribuyeron a que tales regímenes fueran entrando en crisis, a medida que las transformaciones económico-sociales por ellos puestas en marcha, fueron agudizando las desigualdades sociales y evidenciando las contradicciones de las estructuras de dominación sobre las que se sustentaron.

"La paradoja del populismo está en que se funda en un pacto de clases sociales, o en sus grupos más activos, que siguen desarrollándose como tales a lo largo de toda la duración del pacto. Por consiguiente, la alianza de clases sociales implicada en este tipo de política no se rompe únicamente por las divergencias y antagonismos con las 
otras categorías sociales, o debido a las ambigüedades e incertidumbres de las fuerzas populistas en cuanto a sus medios y fines. Cuando se rompe la alianza populista, esta ruptura ocurre también, y a veces principalmente, por causa de las contradicciones desarrolladas entre las clases que componen el propio populismo. ${ }^{23}$

\section{Las bases politico-institucionales}

A diferencia de la típica debilidad que caracterizó al aparato estatal en Latinoamérica durante el período de vigencia de los regímenes oligárquicos, en los populismos el aparato político-institucional del Estado adoptó una función claramente determinante, reforzando de modo significativo su papel como agente del desarrollo económico, de dinamización de la vida política y de conducción de las masas.

Las masas populistas, tanto por sus acciones como por la manera en que fueron manipuladas, posibilitaron una transformación de la estructura y de las funciones asignadas al Estado. ${ }^{24}$ Éste durante los populismos asumió un planteamiento de las relaciones exteriores de distinta orientación al del modelo agrario-exportador vigente durante los regímenes oligárquicos. En el interior, el Estado se manifestó como una nueva articulación, a escala nacional, de los grupos y de las clases sociales.

Torcuato S. Di Tella, considera que los populismos requieren para ser comprendidos ser ubicados en el marco de los específicos procesos de mudanza social que caracterizan a Latinoamérica en el período que va de los años veinte a los sesenta. Se trata de un contexto en el que grandes masas de población urbana recién llegadas de las zonas rurales experimentan lo que este autor denomina como un "efecto de deslumbramiento", originado por el simple hecho del gran cambio que supone pasar de la vida rural a la urbana, por el efecto de la educación o por la influencia de los medios de comunicación de masas. Las transformaciones de índole social y económica que estos fenómenos originan en las masas dan lugar a que en ellas se genere una especie de "revolución de sus expectativas". Como consecuencia de ello, al mismo tiempo que se produce, y con frecuencia se ahonda, un abismo entre las satisfacciones y las aspiraciones, sobre todo en lo ocupacional, las gentes empiezan a experimentar lo que podría ser tipificado como una "inconsistencia de status", es decir, un desajuste entre la

23 Ibídem, págs. 149-150.

24 Ibídem, pág. 17. 
situación que se proponen conseguir y la que en realidad viven. ${ }^{25}$ La inconsistencia de status de la que habla Di Tella se explica también porque, a raíz de los procesos de industrialización y de los cambios sociales y tecnológicos vinculados a ellos, se producen reajustes que se traducen en la eliminación de viejos roles y en la creación de otros nuevos. Estos roles nuevos, que conllevan mejor posición, ingresos, o poder, generan y encauzan ambiciones y esperanzas, ${ }^{26}$ al mismo tiempo que tiende a producirse una conciencia de escasez y sentimientos de inseguridad entre los que se ven desplazados como consecuencia de tales reajustes de roles. Una situación asî suele dar lugar a la emergencia de estados colectivos de incertidumbre, de no saber a que atenerse, así como a situaciones psicosociales de conflicto interno de lealtades potencialmente favorables al arraigo del desconcierto y de la sensación de anomía.

Ante la falta de cultura política y el escaso nivel organizativo de la población, resulta bastante difícil, cuando no imposible, la formación de movimientos políticos u obreros de corte liberal o laboral al estilo de los europeos. En cambio, existe en estas circunstancias un caldo de cultivo muy favorable para que las masas puedan ser fácilmente manipuladas por caudillos carismáticos que legitiman su actuación a través de discursos con frecuencia de naturaleza demagógica. El populismo puede ser conceptuado como un movimiento político que sustenta una ideología anti-statu quo y con un fuerte arraigo popular, cuyas bases o "nexos de organización" son: a) una élite situada en los escalones medios o más elevados de la estratificación y motivada para llevar a cabo una acción anti-statu quo; b) unas masas movilizadas constituidas como resultado de la "revolución de las aspiraciones", y c) una ideología o un estado de agitación social que contribuya a facilitar la comunicación entre los líderes y sus seguidores y a crear una situación de entusiasmo colectivo. ${ }^{27}$

De acuerdo con el planteamiento de Di Tella, la opción por el populismo en Latinoamérica sería un efecto de la existencia en esta zona de unas específicas circunstancias socio-políticas que, a la vez que favorecen el establecimiento de las alianzas populistas, dificultan el funcionamiento de la democracia representativa, de un lado, y de los partidos genuinamente

25 Di Tella, Torcuato S.: "Populismo y reforma en América Latina", en Desarrollo Económico, Vol. IV, n. ${ }^{\circ}$ 16, Buenos Aires, 1965, págs. 391-425.

26 Estas afirmaciones son el resultado de una lectura no literal de Gerth, H. y Wright, Mills C.: "Cambio histórico-social”, en Johnson y otros, El Cambio Social, Buenos Aires, 1967, págs. 82-83.

27 Di Tella, T.: "Populismo y reforma ...”, pág. 398. 
obreros, por otro. No obstante, la interpretación de Di Tella, si bien refleja la naturaleza policlasista de la coalición populista, no especifica nada acerca de las asimetrías existentes en el seno de la misma, que al fin y al cabo es una alianza entre sujetos socio-políticos desiguales, en la que, con bastante asiduidad, acaban siendo hegemónicos los intereses de las clases medias y altas burguesas.

\section{Las bases simbólico-legitimadoras}

El personalismo y el autoritarismo característicos de los regímenes oligárquicos seguían siendo rasgos típicos de los populismos. No obstante, a diferencia de la individualizada e imprecisa estructura de poder sobre la que solía sustentarse el dominio de los caudillos tradicionales, la autoridad de los líderes populistas se apoyaba, en gran parte, en su capacidad para impulsar y encauzar las actuaciones de la sociedad, así como en el usual recurso a la movilización de las masas y en la articulación, por parte del aparato estatal, de complejas modalidades de organización del poder político. En el caso de México, estas modalidades llegaron a estructurarse en un sistema de dominación estable que permitió la institucionalización y la rutinización del carisma más allá de la encarnación de éste en personajes individuales específicos.

Por consiguiente, durante la etapa de vigencia de los populismos se generó una situación, en la que existían unas condiciones especialmente adecuadas para la reproducción o el reforzamiento de la dominación carismática, que dejaba de ser la manifestación ocasional que había constituido durante el período oligárquico y pasaba a erigirse en una de las características fundamentales del ejercicio del poder en esa etapa.

De acuerdo con Max Weber, el carisma conlleva "una variación de la conciencia y de la acción, con reorientación completa de todas las actitudes frente a las formas de vida anteriores o frente al 'mundo' en general". ${ }^{28}$ Tanto las actuaciones de los líderes populistas como las emociones y aspiraciones de las masas que se aglutinaron en torno a ellos estaban imbuidas de (o contribuían a reproducir) una ilusión colectiva de renovación completa y de ruptura con el período oligárquico. Los discursos populistas manifestaban ese anhelo colectivo de ruptura con el pasado y de reno-

28 Weber, Max: Economía y Sociedad, México, 1979, págs. 196-197. 
vación característico de la situación potencialmente carismática en la que se elaboraban. Así, como señala Jorge Graciarena, ideológicamente, los movimientos populistas se caracterizaban por participar de una retórica legitimadora de sus actuaciones que iba dirigida contra la oligarquía y el sistema establecido; en general, estaban definidos de una forma vaga y con un lenguaje que no se expresaba en términos de una explícita lucha de clases.

\begin{abstract}
"Se podría así hablar de pobres y ricos, de trabajadores y ociosos, o de 'descamisados' como le gustaba hablar a Perón, pero para que esa apelación tenga eficacia sobre diversos sectores de la clase media, los movimientos nacional-populares han evitado utilizar muy abiertamente la terminología clasista. Otros componentes de importancia en su ideología, han sido el nacionalismo y el antiimperialismo, temas que pueden servir para convocar y aglutinar a una clase media desarrollista. De todos modos, la ideología es secundaria en estos movimientos, pues para tener efecto tiene que volverse 'personalizada'. La fuente de poder es aquí el líder y no la ideología, de modo que los contenidos de ésta pueden ser variados por el líder con cierta libertad. Lo que es importante para la legitimidad de la ideología es que ésta emane del líder, sea su ‘creación' y no la de otros ideólogos". ${ }^{29}$
\end{abstract}

Tanto la movilización de las masas llevada a cabo por los populismos, como la consiguiente incorporación de las mismas al proyecto del Estado, contribuían a propiciar la adhesión de la población a las proclamas y principios legitimadores de aquél.

El considerable arraigo social alcanzado por las estrategias de movilización colectiva y la retórica legitimadora de los regímenes populistas está relacionado con el hecho de la inexistencia de instituciones políticas -por ejemplo, una infraestructura o sistema de partidos- apropiadas para la movilización de las masas y su incorporación al orden establecido de legitimidad política. Todo ello, ante la ausencia de canales institucionalizados de participación colectiva, y consiguientemente de cultura política, en los países en los que arraiga el populismo.

“[El populismo] ha negado frecuentemente los valores básicos de la democracia representativa, tales como las libertades civiles, al mismo tiempo que efectivamente incorpora a las viejas capas marginadas a la vida económica, cultural y política de la nación. Induce su participación obligatoria en el proceso de nacionalización y determina el paso de la aceptación pasiva a la participación activa. Este régimen adopta un

29 Graciarena, Jorge: Poder y clases sociales en el desarrollo de América Latina, Buenos Aires, 1967, pág. 131-132. 
modelo de desarrollo basado en el planteamiento centralizado y extensivo, si no es que en una nacionalización total...". [El populismo] "puede surgir en países en los que...la democracia representativa...no alcanza cierto nivel de estabilidad"..$^{30}$

\section{A manera de conclusión}

Más allá de las diferencias existentes entre las distintas manifestaciones del populismo, es posible encontrar una serie de características comunes en la estructura social latinoamericana que lo sustentó. Características que se han tratado de sistematizar en los tres epígrafes anteriores y que, conjuntamente, hacen explicable el generalizado arraigo de este fenómeno socio-político en dicha estructura social. En primer lugar, tanto en México como en Argentina y Brasil (los tres casos tomados como referencia en este trabajo), los gobiernos de índole populista resultaron de la emergencia de movimientos de masas y de la creación y actuación de partidos políticos de naturaleza policlasista. ${ }^{31}$

En segundo lugar, dichos gobiernos llevaron a cabo significativas reformas en distintos aspectos del sistema político-económico, como en lo relativo al movimiento de capitales nacionales o extranjeros, o en el ámbito de las propias relaciones de producción. En los tres casos, resultó una significativa modificación de la fisonomía del aparato estatal y, como consecuencia, cambió la relación del Estado con la sociedad.

En tercer lugar, el varguismo, el cardenismo y el peronismo impulsaron políticas encaminadas a propiciar el desarrollo económico, específicamente la industrialización, o la sustitución de importaciones. La manera de acuerdo con la cual reformularon las relaciones del Estado con la economía estaba relacionada directamente con la transición de las "economías de enclave", características del período oligárquico, a unos sistemas económicos más diferenciados y dirigidos a desarrollar un mercado interno, paso que suele ser usual en los procesos de construcción y de integración del Estado-nación.

En cuarto lugar, tanto la composición como la evolución seguida por el populismo estructural mexicano, el varguismo y el peronismo, manifiestan las contradicciones y fragilidades de la más o menos precaria alianza de

30 Germani, Gino: "Political Change: from Traditional Society to Total Participation in Latin América" en Society and Politics in Transition in Latin América, Nueva York, 1965, pág. 6.

31 Ianni, O.: La formación del Estado..., págs. 19-20. 
clases que dio lugar al afianzamiento de sus respectivas estructuras de poder y determinó sus posteriores desarrollos.

En el contexto sociohistórico latinoamericano en el que se desarrollaron los procesos populistas, como el proletariado era relativamente escaso, el pueblo, que era un concepto más ambiguo y generalizante, sirvió de substrato de articulación y de legitimación del impulso dado a la conformación del Estado-nación a raíz de tales procesos. Además, a diferencia de la generalidad de los populismos, en los que el Estado y lo político-urbano-industrial se manifiestan, sobre todo, como referentes de rechazo, el caso latinoamericano evidencia que es desde el propio Estado, desde donde se impulsa el populismo, especialmente, como un intento de articular un proyecto de autonomía nacional encaminado a responder a las exigencias y demandas contradictorias de la sociedad. Una sociedad que fluctúa entre las tentativas de mantenimiento (o de mirada hacia) la tradición y las que dirigen su atención hacia la modernidad, entre lo urbano y lo rural, entre las expectativas o proyectos de cambio y de regulación social de las masas rurales recién emigradas a las ciudades y las exigencias de unas clases medias urbanas que, a fin de garantizarse su propio espacio, han de enfrentarse al imperialismo plasmado en el sistema agro-exportador sobre el que se sustentaba el dominio de las oligarquías latinoamericanas. De esta forma, tanto las clases medias como los elementos de la población rural que las secundan tienen sobrados intereses para oponerse al imperialismo, aunque, obviamente, cada una de ellas entiende esta oposición de manera diferente y alberga propósitos distintos en su expectativa de autonomía nacional.

El nacionalismo característico de la retórica legitimadora de los populismos puede ser entendido como una tentativa de las sociedades latinoamericanas de dirigir su atención como colectividades hacia los problemas y posibilidades internas. Ello, después de la mirada hacia afuera (especialmente hacia los EE.UU. o hacia Europa) que había marcado la dinámica de funcionamiento y de legitimación de los regímenes políticos del período oligárquico. ${ }^{32}$ Nacionalismo que, aunque era más doctrinario que real, y en gran parte estaba motivado por los acontecimientos exteriores de la época en la que se generó (especialmente, la II Guerra Mundial), también signifi-

32 Esta mirada hacia fuera se sustentaba en la desmedida admiración que se sentía frente a la cultura y los referentes político-institucionales anglosajones, que eran considerados como el paradigma de civilización frente a la barbarie atribuida a Latinoamérica. Un ejemplo de este punto de vista es Sarmiento, Domingo Faustino: Civilización y Barbarie, Buenos Aires, 1962. 
caba para muchos de los que de él participaban una voluntad consciente y decidida de autonomía; expresada ésta en la adopción de medidas, tales como la ya referida estrategia del desarrollo económico fundamentado en la sustitución de importaciones.

A pesar de los condicionamientos exteriores que lo motivaron y de sus limitaciones, el populismo supuso un paso decisivo en el proceso de forja del Estado-nación en Latinoamérica, ya que contribuyó especialmente al incremento de los niveles de integración económico-social y político-institucional de dicho Estado, a la vez que a aglutinar la conciencia colectiva en torno a unos proyectos articuladores de los marcos simbólico-legitimadores de la nacionalidad que, aunque evidentemente tendían a ocultar la existencia de fisuras y contradicciones entre las clases que integraban el frágil equilibrio que los sustentaba, repercutieron bastante en el arraigo de una conciencia común de pertenencia a una misma nación. Conciencia de nacionalidad, que, sin duda, contribuyó a incrementar los niveles de legitimidad del proyecto populista de Estado impulsado institucionalmente desde el aparato de éste al que la misma simbolizaba. Todo ello se llevó a cabo de acuerdo con una legitimación nacionalista "popular", que no estaba exenta de las ambigüedades inherentes a los términos nación y pueblo. 